\title{
An Integrated Spatial Method for Minimizing Environmental Damage of Transmission Pipelines
}

\author{
Volkan Yildirim ${ }^{1}$, Tahsin Yomralioglu², Recep Nisanci', Ebru Husniye Colak ${ }^{1}$, \\ Sevket Bediroglu ${ }^{1 *}$, Tugba Memisoglu ${ }^{1}$ \\ ${ }^{1}$ Faculty of Engineering, Karadeniz Technical University, Turkey \\ ${ }^{2}$ Faculty of Civil Engineering, Istanbul Technical University, Turkey
}

Received: 12 January 2016

Accepted: 11 June 2016

\begin{abstract}
Pipelines are essential for transporting energy resources over long distances. Pipeline projects cause many environmental, economic, and social problems. The construction of large-scale infrastructures such as natural gas/oil pipelines involves extensive disturbance for regional ecosystems. Therefore, it is very important to ensure bad effects of transmission pipeline routes considering environmental sensitivities. In order to do this, we used a geographical information system with multi-criteria decision-making techniques to create an environmental care model. In this study, we applied the order preference by similarity to ideal solution technique to integrate environmental sensitivity into the planning of a natural gas transmission pipeline project. For this purpose, route optimization was carried out for the ongoing operation of an existing $84.33 \mathrm{~km}$ natural gas transmission line. An environmentally sensitive optimum route was determined according to environmental impact assessment criteria. The experimental studies confirmed that our road is superior to the current road when compared with the 13 spatial criteria used for analysis. Our road has only seven stream passes while the current road has 20 , our road has no quality soil pass on the other side while the current road has a $661-\mathrm{m}$ quality soil pass, and our road is more cost-efficient at $77.89 \mathrm{~km}$ as opposed to the current road's $84.33 \mathrm{~km}$.

This paper declares that optimized and sophisticated GIS-multicriteria decision method tools/models solve natural gas transmission project routing problems in terms of environmental sensitivities and cost efficiency.
\end{abstract}

Keywords: geographical information system, multicriteria decision making, spatial TOPSIS, pipeline, energy

*e-mail: bediroglu@ktu.edu.tr 


\section{Introduction}

In terms of cost and efficiency, a transmission pipeline (TP) is one of the most efficient tools for transporting liquid resources over long distances. Transportation of water, natural gas, crude oil, and petroleum products plays a very important international role [1-3]. Various disciplines such as engineering, surveying, mapping, route determination, geographical information systems (GIS), construction, and especially issues concerning safety and the environment are involved in pipeline projects. The route determination process is a vital stage in planning TP projects [4-6]. A particular significance is route determination processes that involve building over long distances and wide corridors. One of the most important factors in accurate transmission line project planning is optimum route selection [4, 7]. In practical applications, TP routes are determined using conventional methods. The basic process employed in the conventional method involves selecting the shortest route between the starting point and final point as marking on topographical maps. At these applications a few criteria besides slope are considered. This causes a limited perspective, so determined results with this method can harm the application.

A total of $145,004 \mathrm{~km}$ of new oil and gas pipeline is scheduled to be constructed across various regions of the world by 2018. Between 2014 and 2018 more new pipelines $(58,981 \mathrm{~km}$ in total) will be built in Europe, the Middle East, and Africa than in any other region, accounting for about $41 \%$ of the total of globally planned pipeline additions during this period. According to this data, pipeline and transport activity will continue to be seen in the future. In this context - especially in developing countries such as Turkey that are specified as energy corridors - it is important to determine optimum routes, corridors, etc. [8-10]. Choosing the wrong methods can effect environmental resources in a bad way. Goals of any project must be achieved in real measure. The performance indicators are more useful in these areas. They provide measurable aspects of an organization, carefully handpicked to be representative [11].

The problem of route selection as referred to route planning, choosing an optimum route, corridor analysis, and site selection can be solved using the GIS-based leastcost path analysis (LCPA) method. This process offers an important opportunity for stakeholders [4, 7, 12-16]. GIS technology has shown rapid development in recent years and has proven to be an effective tool in route selection. Graphic and non-graphic information can be gathered by GIS and made available for processing stages [17-19]. Moreover, GIS technology (known as spatial decision support systems) can be integrated easily with other methods to provide great advantages for decision makers conducting LCPA studies [16, 20-21]. According to Pinto et al., the MCDM considered time savings due to easier access; gains in productive time and reduced health care costs saved due to less illness, and prevented deaths [22].
Choosing an appropriate TP route is a helpful task for which GIS and the MCDM methods [19-20, 23] provide significant support for the generation and comparison of alternatives, taking into account the evaluation criteria through the active participation of experts and stakeholders involved in the decision-making process. The MCDM offers a set of procedures, techniques, and algorithms for structuring decision problems, and for designing, evaluating, and prioritizing decision alternatives. Location problems include strong spatial dimensions, as a large number of spatial variables are involved, such as the proximity to rivers, roads, or populations, and spatial characteristics of the region including geology, slope, and soil type, among others. GIS is designed to store, manage, analyze, and visualize the geospatial data required by decision-making processes [14, 24-27].

In recent years there has been a rapid expansion of interest and research on GIS-based, Spatial MCDM (S-MCDM) methods. The S-MCDM is a routine activity that is common to individuals and organizations. People make decisions influenced by location when they choose a store to shop, a route to drive, or a neighborhood to live in. Organizations are not much different in this respect. They consider the realities of spatial organization when selecting a site, choosing a land development strategy, allocating resources for public health, and managing infrastructures for transportation or public utilities [18, 28-34]. Solving spatial-based decision problems usually requires an intelligent and integrative use of information, domain-specific knowledge, and an effective means of communication. Although GIS and MCDM play important roles in solving spatial decision-making problems, each of these tools has its own limitations in dealing with such problems. For example, GIS is a great tool for handling physical suitability analysis. However, it has limited capabilities for incorporating the decision makers' preferences and heuristics into the problem-solving process. There is a wide range of related methodologies, including S-MCDM, that aim at solving "real-world" GIS-based planning and management problems. They offer a variety of techniques and practices incorporating knowledge from various disciplines and integrating the preferences of the decision makers [35].

This paper investigates using GIS and MCDM methods jointly for the purpose of determining optimum NGTP routes. Previous studies considered some parts of these techniques, but not all. We have created a contextspecific GIS extension at related scientific research project (TUBITAK-111Y041). All the route determination analysis and, afterward, alternative route evaluations of determined routes were done automatically with the help of the extension. The project area consists of rich environmental and historical resources. By this study a new environmental friend and economic route determination approach for similar applications was generated. This will be a good treatment for future systems on similar projects. 


\section{Materials and Methodology}

In particular, the accurate and effective planning of TP projects makes an important contribution to lowering project costs, eliminating potential risks, and reducing environmental problems in the construction process of long-distance linear engineering structures. The most important step in the planning activities of TP projects is an applicable route selection. There are significant advantages for choosing appropriate routes using GISbased analysis of the LCPA with an integrated S-MCDM method such as S-TOPSIS.

According to CRUZ and Marques, using MCDM entails several advantages. For instance, such a framework: 1) allows for the inclusion of all types of criteria; 2) the objectives, criteria, scores, and weights are explicit and transparent, allowing for open discussion; 3 ) the decisionmaking process is participatory and can be documented, facilitating communication, auditing, and review; 4) the measurement of each particular factor (criterion) can be carried out by external experts; 5 ) it is possible to compute partial and global scores, which can be very informative for policy-making; 6) methodologies for assigning scores and weights conforms to sound theoretical principles; and 7) the whole process can be supported by computer-based tools, which speeds up decision making [36].

A description of the route selection process for the TP project in which some of the limitations and economic feasibilities are presented is shown in Fig. 1. All components and restrictions in the construction of the TP project are directly related to route selection. In many cases, the ideal route can be considered as a straight line between the starting and ending points. However, topographical, environmental, conceptual, and technical limitations can change the route. A variety of factors must be considered in the selection of the most appropriate route for the TP in environmental terms.

The research method in this article consisted of seven steps. The first step was the detection of environmental sensitivities according to the environmental impact assessment (EIA) report. In the second step, the pipeline operation area was determined (Fig. 2). In the third step, factors and sub-factors affecting environmental resources

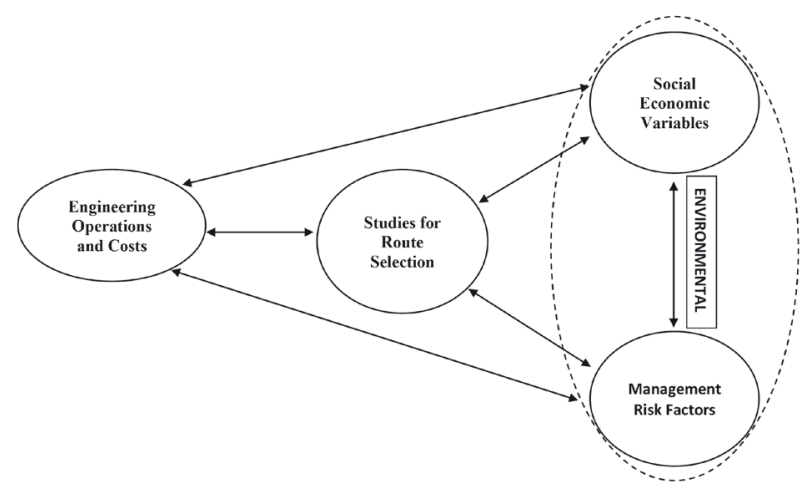

Fig. 1. Effect cycle of a route selection.

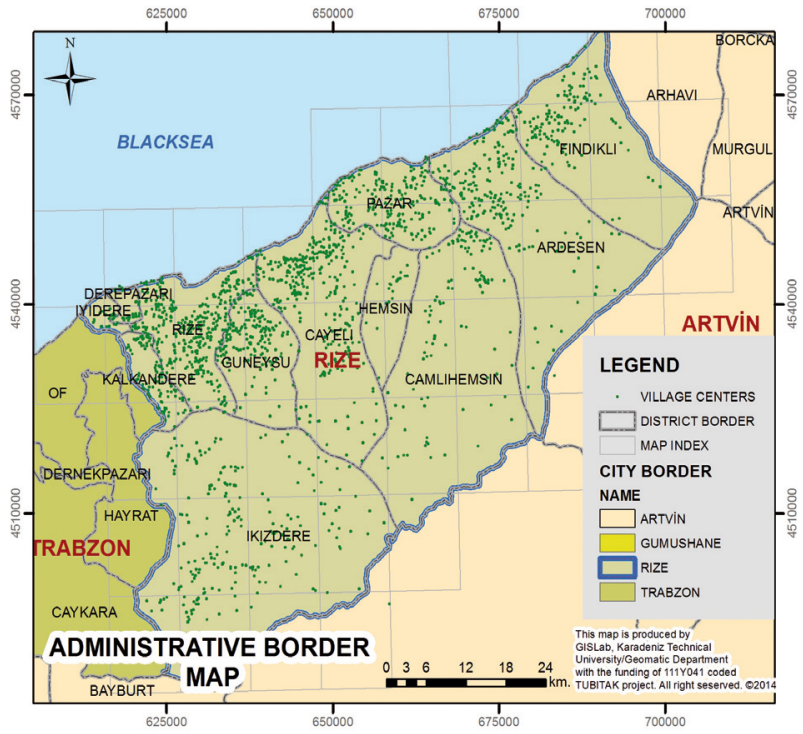

Fig. 2. Study area administrative border map.

within a TP project were determined, and weights of these factors and sub-factors were calculated. In the following step, the data required to determine the route, taking into account environmental awareness, was collected within the boundaries of the study area. In this step, existing data from regional institutions, satellite images, GPS data, soil data, natural resource data, hydrology data, geology data, and standard 1/25,000-scale topographical maps were used and the data organized in a spatial database with ArcGIS. In the fifth step, the optimum environmental route was determined based on S-TOPSIS and LCPA using the weights of the factors affecting the route. The final step was to compare the current route and optimum route with the results of field studies and spatial data and to discuss the results. Fig. 3 shows this multistage workflow and organization are shown.

\section{S-TOPSIS}

The spatial technique for order preference by similarity to ideal solution (S-TOPSIS) method is currently used to identify solutions that are as close as possible to an ideal solution while applying some measure of distance; consequently, indicated solutions are called compromises. The main idea of TOPSIS is that the solution should be as far as possible from the worst possible solution and as close as possible to the best possible solution. This method is quite simple and intuitive, presenting a satisfactory performance in many applications [30, 37-38].

The TOPSIS method has four advantages: 1) a sound logic that represents the rationale of human choice, 2) a scalar value that accounts for both the best and worst alternatives simultaneously, 3) a simple computation process that can be easily programmed, and 4) performance measures for all alternatives that can be visualized on a polyhedron for any two dimensions. TOPSIS can be expressed in a series of steps [39]. There are many different 


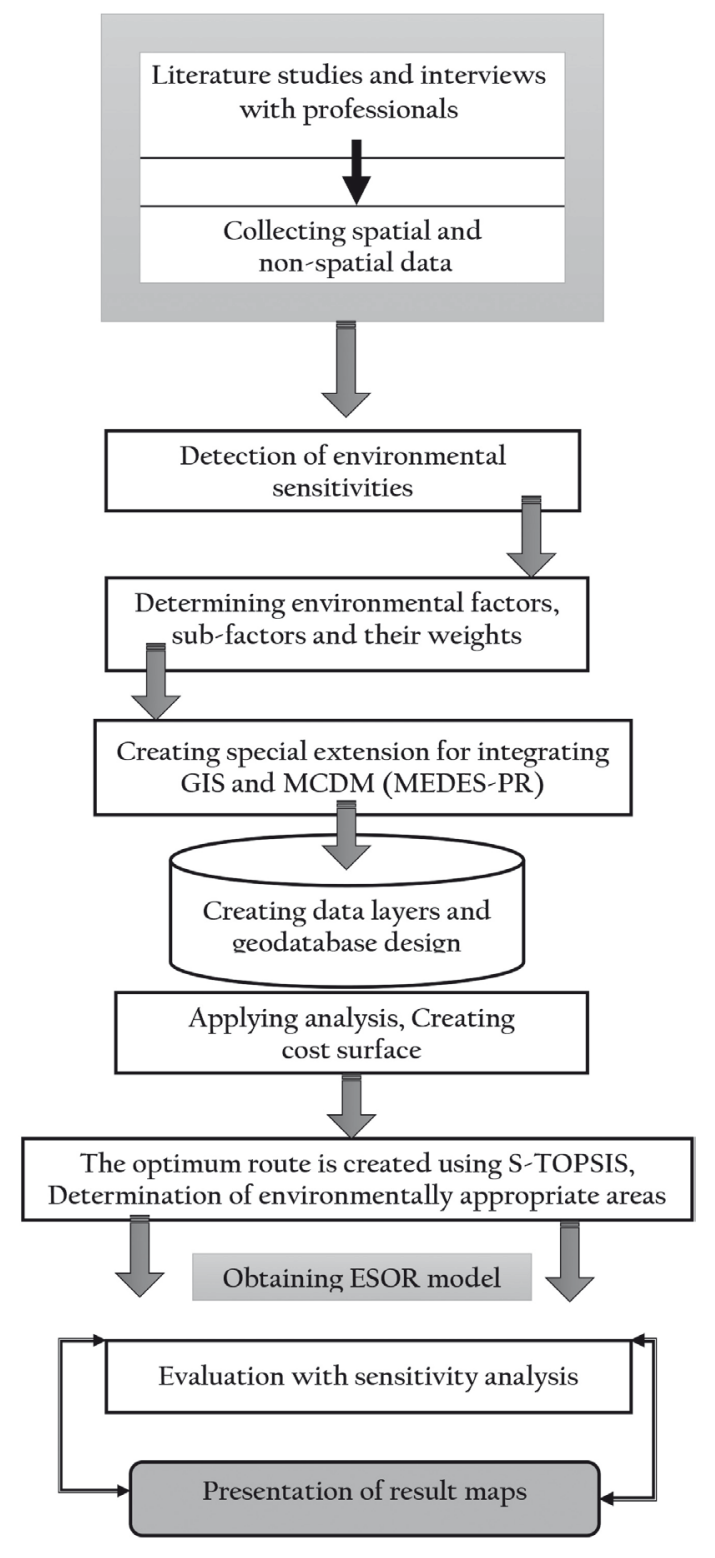

Fig. 3. Case study workflow - organization of paper.

variables at the equation sequence of TOPSIS calculation and these variables are defined below:

$\mathrm{D}=$ decision matrix

$\mathrm{A} 1, \ldots \ldots, \mathrm{An}=$ value corresponding to $j$ th alternative

$\mathrm{F} 1, \ldots \ldots, \mathrm{Fn}=$ value corresponding to $i$ th criteria (factor)

$\mathrm{R}(=[\mathrm{rij}])=$ normalized decision matrix

$\mathrm{Vij}=$ weighted normalized matrix

$\mathrm{Wi}=$ weight of any criteria (factor)

$\mathrm{A}^{+}=$positive ideal solution

$\mathrm{A}^{-}=$negative ideal solution

$\mathrm{Dj}^{+}=$separation measures to positive-ideal solution

$\mathrm{Dj}^{-}=$separation measures to negative-ideal solution

$\mathrm{CCj}^{+}=$relative closeness to the ideal solution

Step 1: Establish a decision matrix for the ranking. The structure of the matrix can be expressed as follows:

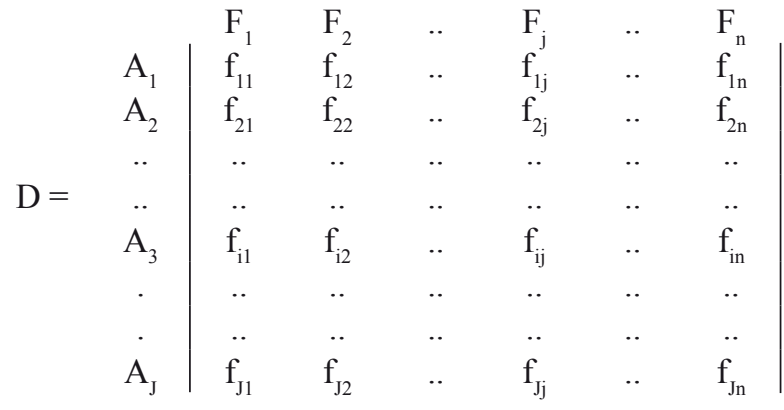

...where $A_{j}$ denotes the alternatives $j, j=1,2, \ldots, J ; F_{i}$ represents the $i$ th attribute or criterion, $i=1,2, \ldots, n$, related to the $i t h$ alternative; and $f_{i j}$ is a crisp value indicating the performance rating of each alternative $A_{i}$ with respect to each criterion $F_{j}$.

Step 2: Calculate the normalized decision matrix $R\left(=\left[r_{i j}\right]\right)$. The normalized value $r_{i j}$ is calculated as

$$
r_{i j}=\frac{i j}{\sqrt{\sum_{j=1}^{n} f_{i j}^{2}}}, \quad j=1,2, \ldots, J ; \quad I=1,2, \ldots, n
$$

Step 3: Calculate the weighted normalized decision matrix by multiplying the normalized decision matrix by its associated weights. The weighted normalized value $v_{i j}$ is calculated as

$$
V_{i j}=w_{i} \times r_{i j^{\prime}} \quad j=1,2, \ldots, J ; \quad I=1,2, \ldots, n
$$

...where $w_{i}$ represents the weight of the ith attribute or criterion.

Step 4: Determine the positive-ideal and negative-ideal solutions.

$A^{+}=\left\{v_{1}^{+}, v_{2}^{+}, \ldots, v_{i}^{+}=\left\{\left(\operatorname{maxv}_{i j} \mid i \in I^{\prime}\right),\left(\operatorname{minv}_{i j} \mid i \in I^{\prime \prime}\right)\right.\right.$

$A^{-}=\left\{v_{1}^{-}, v_{2}^{-}, \ldots, v_{i}^{-}=\left\{\left(\min _{i j} \mid i \in I^{\prime}\right),\left(\max _{i j} \mid i \in I^{\prime \prime}\right)\right.\right.$

...where $I^{\prime}$ is associated with the positive criteria, and $I^{\prime \prime}$ is associated with the negative criteria.

Step 5: Calculate the separation measures using the n-dimensional Euclidean distance. The separation of each alternative from the positive-ideal solution $\left(D_{j}^{+}\right)$is given as

$$
D_{j}^{+}=\sqrt{\sum_{i=1}^{n}\left(v_{i j}-v_{i}^{+}\right)^{2}}, \quad j=1,2, \ldots, J
$$


Similarly, the separation of each alternative from the negative-ideal solution $\left(D_{j}^{-}\right)$is as follows:

$$
D_{j}^{-}=\sqrt{\sum_{i=1}^{n}\left(v_{i j}-v_{i}^{-}\right)^{2}}, j=1,2, \ldots, J
$$

Step 6: Calculate the relative closeness to the ideal solution and rank the performance order. The relative closeness of the alternative $A_{j}$ can be expressed as

$$
C C_{j}^{+}=\frac{D_{j}^{-}}{D_{j}^{+}+D_{j}^{-}}, \quad j=1,2, \ldots, J
$$

Since $D_{j}^{-} \geq 0$ and $D_{j}^{+} \geq 0$, then clearly $C C_{j}^{+} \in[0,1]$. The larger the index value, the better the performance of the alternatives. The factor and sub-factor weights were calculated using TOPSIS.

\section{GIS-Based Least Cost Path Analysis}

Route problems including route selection, route planning, and optimal route determination can be solved using LCPA based on GIS technologies. The LCPA can be carried out on both vector-based and raster-based data from a non-defined space [40]. Most of the time this can be linked respectively to the vector and raster modeling alternatives, where vector data of an existing network are used to build a network topology manageable by algorithms operating on graphs; however, the last option appears to be more adequate for exploring free terrain to locate a usable path [41]. Because of the advantages of LCPA observed in prior studies, the LCPA algorithm was chosen for the present study. Due to the input criteria such as factors and sub-factors, it was used with GIS for determining the optimum route.

\section{Case Study}

\section{Study Area}

A suitable area of $3,946 \mathrm{~km}^{2}$ between the latitudes of $40^{\circ} 20^{\prime}$ and $41^{\circ} 15^{\prime} \mathrm{N}$ and longitudes of $40^{\circ} 22^{\prime}$ and $41^{\circ} 28^{\prime} \mathrm{E}$ in Rize Province, Turkey, was selected as the study area (Fig. 2). Rize includes one of Turkey's most important ecological regions as the majority of land in the coastal strip of Rize produces special types of agricultural products. The rugged geographical area exhibits botanical diversity and hosts numerous rare species. Approximately $75 \%$ of the province evaluated in terms of land cover consists of tea plantations and forest areas. The remaining areas are filled with pasture, open land, settlements, and other agricultural activities. Approximately $70 \%$ of Rize consists of over $40 \%$ slope areas. Rize generally consists of mountainous areas with numerous streams. The combined length of all the watercourses in the province is more than $5,000 \mathrm{~km}$. There is also a long road network in Rize, with a total length of rural roads being more than $6,000 \mathrm{~km}$. In 2014 the population of Rize was 329,779 [42].

\section{Determining Environmental and Cost-Effective Factors and Creating a Geographic Database} (Geodatabase)

The TP factors defined for the least environmental damage are soil, land cover, stand type (forest), plant type, river, lake, historically protected areas, and flora/ fauna. Other factors that affect TP routing are population, slope, geological structure, avalanche risk, and roads. Harmonization of these environmental and cost-effective factors via GIS and MCDM gives the optimum applicable routes for establishing pipelines. The factors and subfactors were defined with the result of literature studies and interviews with academicians and practitioners working on this subject. Spatial and non-spatial data were collected according to these factors, data layers were created, and the geodatabase was generated.

Environmental constraints, laws, and existing assessments relating to the environmental impact assessment(EIA) report had to be considered in the selection of the TP route. EIA is a concept used for evaluation of positive and negative results of the environmental impacts of program and policy (Wikipedia, 2016). In other words, EIA is usually used when applied to concrete projects and applies to policies, plans, and programs. EIA is based on the extent to which environmental impacts can be identified, evaluated, and mitigated. EIA is a standard requirement as supported by the World Bank, whose projects require a significant change in land use and protection of environmentally sensitive areas. The aim of EIA is also to ensure effective opportunities to participate in the decision-making procedure. In this study, EIA legislation is used to evaluate minimizing environmental damage and it is considered in the evaluation of the factors used in the TP projects.

Study area data was compiled with ArcGIS 10.1 software. The database prepared in this software included a geodatabase with vector and raster dataset features. The geodatabase consisted of the received data. A single database was created for both raster and vector data. The graphic view of some layers in the geodatabase are shown in Fig. 4.

\section{Creating Special GIS Extension}

We have generated a special GIS extension using ArcGIS developer SDK and Visual Studio by integrating the programing languages Python, $\mathrm{CH}$, and ArcObjects Library. The name of the extension is Multicriteria Extension for Determining Environmentally Sensitive Pipeline Routes (MEDES-PR). The functionality of the extension is gathering GIS and MCDM features within the same interface for finding optimum routes. The extension only needs vector-based GIS data, and afterward all the 
vector-raster conversations, complicated GIS analyses (buffer, interpolation, clip, erase, cost distance, cost path), weight assignments, and calculations can be done automatically due to the give factor and sub-factor weights. A pair-wise comparison and TOPSIS formulas have been implemented in the extension. We named the
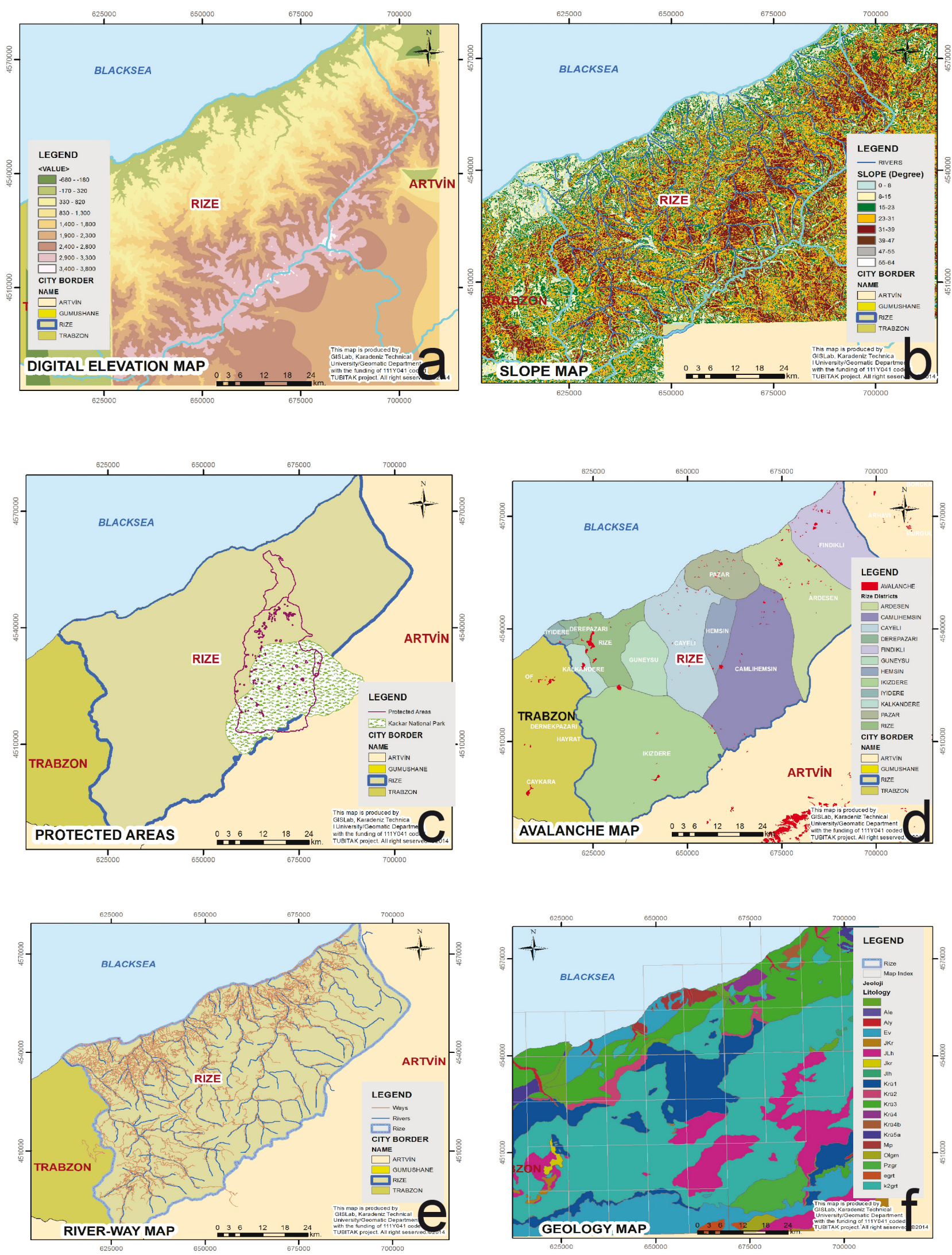

Fig. 4. Graphic view of the geodatabase. 
optimum route determined using MEDES-PR as the environmentally sensitive optimal route (ESOR).

\section{Case Study Analyses}

GIS-based S-MCDM analysis was applied with the collected geospatial database at the direction of steps explained briefly in the methodology section. We have made all analysis with our case-sensitive TP route planning extension. Analysis steps are simply explained below. The first step is creating ring buffers to point or line vector data (rivers, ways) in the affected zone as $100 \mathrm{~m}, 200 \mathrm{~m}$, etc. The second step is that interpolation of density data, such as population with Kriging or height with IDW and TIN creation. The third analysis step is classifying polygonal data such as soil, geology, or land use. The fourth step is transforming all these prepared data to raster format and reclassifying these raster data with normalization techniques. In these processes, all data layers were formed using raster-based standard pixel sizes. The pixel sizes were determined depending on the scale of the used spatial data as $50 \mathrm{~m}$ in order to avoid loss of data. And finally, we calculated accumulated cost surface with TOPSIS formulas included in the extension. Then cost distance and cost path analysis were done for determining the optimum route-caring environment.

A summary of TOPSIS calculations is: 1) the first step is calculating normalized sub-factor values with the formula $\mathrm{x}_{\mathrm{ij}} / \mathrm{xMax}, 2$ ) calculating factor weights with pair-wise comparison method, and 3) calculating TOPSIS matrix results according to given formulas with weighted matrix and minimum-maximum matrix. A pair-wise comparison and normalized weight table are given in Table 1.

According to the EIA evaluation, the criteria were determined through the creation of a cost surface map. The

Table 1. Weights of factors.

\begin{tabular}{|c|c|}
\hline Factor & $\begin{array}{c}\text { Weights from Pair-wise } \\
\text { comparison }\end{array}$ \\
\hline Land Cover & 0.179 \\
\hline Soil & 0.166 \\
\hline Stand Type (Forest) & 0.138 \\
\hline River & 0.145 \\
\hline Historically Protected Areas & 0.100 \\
\hline Flora-Fauna & 0.081 \\
\hline Lake & 0.069 \\
\hline Population & 0.033 \\
\hline Slope & 0.027 \\
\hline Geology & 0.019 \\
\hline Road & 0.018 \\
\hline Avalanche & 0.015 \\
\hline Plant Type & 0.010 \\
\hline
\end{tabular}

surface was divided into 10 land classes, including urban areas, broad-leaved woodland, thin-leaved woodland, grassland, tea plantations, hazelnut orchards, cultivated agricultural land, wetlands, and rocky areas. Woodlands, wetlands, and urban areas were identified as restricted areas for TP transit. According to data from the survey, the transit of these three surface classes was avoided as much as possible. It was foreseen that transits of rivers, streams, and other watercourses would be limited, and a small number of road transits would be necessary in order to reduce the construction activities occurring in the road transit areas. As no transits in proximity to water resources, protected areas, conservation areas, and recreation areas were allowed, transits were planned to pass at a distance outside of these areas. To prevent the degradation of flora and fauna habitats and high-grade agricultural soil classes, transit of these areas was avoided. Provisions were made for protection of summer and winter grassland pastures. Geological and hydrogeological factors and also constraints were considered for slopes in order to minimize excessive splitting of landslideprone embankments. All these factors are essential for the creation of an environmentally sensitive TP route.

\section{Analysis Results and Discussion}

The optimum route was created using S-TOPSIS with GIS-based LCP. At this stage, ArcGIS 10.1 software was used and an extension was created to be able to identify routes through raster data models for the LCPA that was designed on this software using S-TOPSIS. The weight values shown in Table 1 were multiplied with the data layers and the resulting values were designated as the cost value to each layer pixel. A cost surface map had been created (cost) with values assigned as resistance in order to determine the environmental challenges of the TP line in each pixel (Fig. 5). The surface was divided into 10 levels of difficulty in terms of environmental sensitivity with the method reclassify raster. First-degree transit areas were classified as best for environmental care while $10^{\text {th }}$ degree areas were the most difficult transit areas and were crucial in terms of environmental sensitivity.

In accordance with the criteria declared in the Applying Analysis section, an ESOR was determined with S-TOPSIS and its advantages as compared to the current route (CR) are shown in Table 2. The result showing how ESOR is more effective than conventional methods can be easily seen at Table 2. ESOR is advantageous to CR when it is 12 criteria considered separately. CR and ESOR routes were also compared with field studies. Advantageous and disadvantageous aspects of the two routes are clearly seen in the visiting area. There was great coherence between analysis results and field observations. The primary reason for this result lays behind the accuracy and reality of the geospatial data used. 


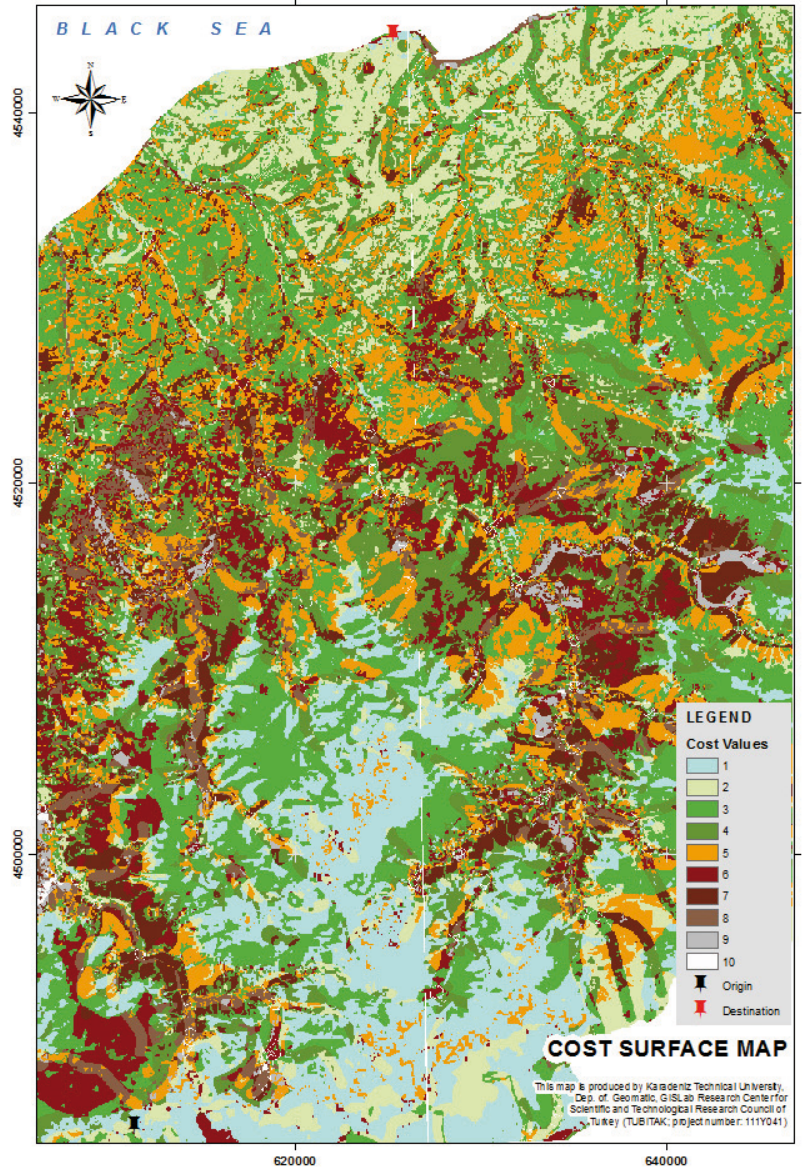

Fig. 5. Accumulated cost surface map.

Table 2. Comparison of routes in terms of environmental criteria.

\begin{tabular}{|c|c|c|}
\hline FACTORS (Criteria) & $\begin{array}{c}\text { ESOR } \\
\text { (suggested road) }\end{array}$ & $\begin{array}{l}\text { Current } \\
\text { Road }\end{array}$ \\
\hline $\begin{array}{l}\text { Transit of hazelnut } \\
\text { agriculture }\end{array}$ & $3,124 \mathrm{~m}$ & $3,828 \mathrm{~m}$ \\
\hline Transit of tea agriculture & $12,891 \mathrm{~m}$ & $15,864 \mathrm{~m}$ \\
\hline Transit of pastures & $3,858 \mathrm{~m}$ & $3,890 \mathrm{~m}$ \\
\hline Transit of rocky areas & $21,491 \mathrm{~m}$ & $33,848 \mathrm{~m}$ \\
\hline Transit of quality soil & $0 \mathrm{~m}$ & $661 \mathrm{~m}$ \\
\hline Intersect with streams & $7 \mathrm{~m}$ & $20 \mathrm{~m}$ \\
\hline $\begin{array}{l}\text { Transit of sensitive } \\
\text { agricultural land }\end{array}$ & $22,689 \mathrm{~m}$ & $24,414 \mathrm{~m}$ \\
\hline $\begin{array}{l}\text { Transit of high slopes } \\
\qquad>\% 50\end{array}$ & $35,185 \mathrm{~m}$ & $37,211 \mathrm{~m}$ \\
\hline $\begin{array}{c}\text { Transit of geologically } \\
\text { hard areas }\end{array}$ & $21,491 \mathrm{~m}$ & $33,840 \mathrm{~m}$ \\
\hline Length & $77,292 \mathrm{~m}$ & $84,333 \mathrm{~m}$ \\
\hline Transit of forest areas & $46,142 \mathrm{~m}$ & $48,566 \mathrm{~m}$ \\
\hline $\begin{array}{l}\text { Intersect with protected } \\
\text { areas }\end{array}$ & $0 \mathrm{~m}$ & $1 \mathrm{~m}$ \\
\hline Proximity to settlement & $720 \mathrm{~m}$ & $1,960 \mathrm{~m}$ \\
\hline
\end{tabular}

*Each value shows passing measure in meters due to the given criteria

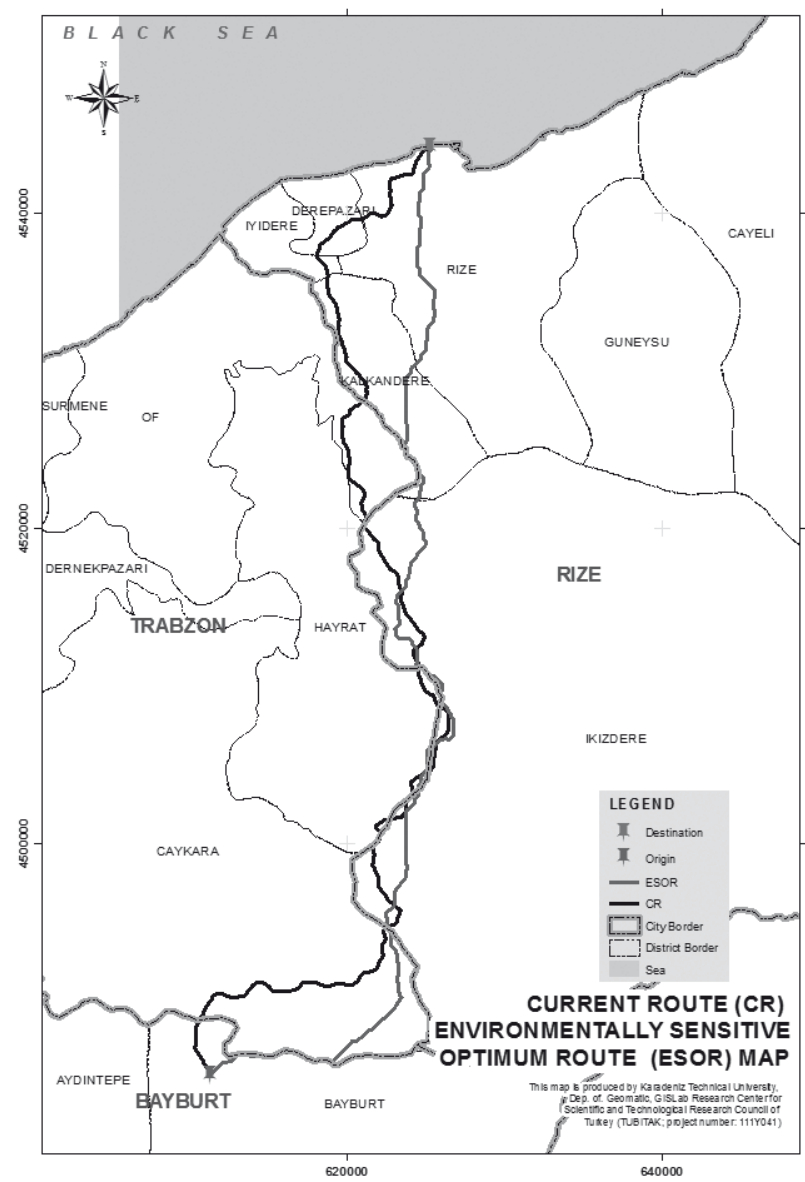

Fig. 6. Current route and optimum route on study area map.

The lowest possible pixel values and the shortest possible route between the initial and final end points in the area were determined automatically by the LCP method on the cost surface map (Fig. 5). The TP START point at the Rize border in the southern part of the study area was the starting point; the end point was at the northern part of the urban distribution area (Fig. 6).

This study was carried out in accordance with the requirements of countries' energy-intensive pipeline activities in order to reduce the environmental damage caused by the identified route. Moreover, its aim was to determine, via an automated process, the environmental sensitivity that is undetectable by conventional route determination methods and to reduce environmental damage caused by the TP project.

Route determination studies made by conventional methods, without questioning the data quality of the standard 1/25,000 scale maps, do not produce effective results. All areas are not fully examined by using classic route corridor analysis, generally known as "narrowing the field"; thus, accurate results cannot be obtained by conventional methods. These methods were used to make a selection from among alternatives for determining the $1,850 \mathrm{~km}$ route for the Trans-Anatolian Natural Gas Pipeline Project (TANAP). This TP is planned to transport natural gas from the Caspian Region through Turkey and then to Europe. This situation is not regarded as an 
appropriate approach for the reduction of environmental damage. In this context, MCDM methods and GIS-based route determination applications are very important.

The ESOR was determined by integrating S-TOPSIS with the GIS-based LCP method, identifying environmental factors and determining the weight of the factors using pairwise comparison matrices in the route determination process. In this process, it was proven that TOPSIS integrated with GIS can be used in this kind of work. In future studies, results can be proven by using other spatial MCDM methods.

In order to determine environmentally sensitive TP routes more precisely, using the improved interface developed in this field study, the weights of environmental factors showing possible regional differences can be dynamically changed. In addition, resulting routes can be determined alternatively. In the case of more than one alternative route, using the improved interface, the process can be repeated and the most environmentally sensitive route among these alternatives can be identified.

At this stage, using updated and accurate data is very important. The accuracy of the identified route is directly related with the quality of the spatial data. It is clear that more effective results can be found by studies that deal directly with actual data obtained from remote sensing and satellite technology. Our model showed that integrating S-TOPSIS with the GIS-based LCP method effectively prevents environmental damage while applying office studies before building TPs.

We have applied sensitivity tests on our geodatabase in order to determine whether or not our weights and data classifications are sensitive to any changes. We have used Dr. Chen and Dr. Yu's AHP_SA tool, which is a special extension to ArcMap working on ArcMap and Matlab programs. We have seen it is an essential and easy tool to use for sensitivity tests. At this study these tests were done with five geographic layers. The extension defined our five layers as stand type, protected areas, soil, river, and land cover (respectively S1, S2, S3, S4, and S5). We have calculated weight sensitivity matrix and sensitivity directions between $\mathrm{S} 1>\mathrm{S} 2, \mathrm{~S} 1>\mathrm{S} 3, \mathrm{~S} 2>\mathrm{S} 4, \mathrm{~S} 5>\mathrm{S} 3$, etc. All the results were fulfilling and these tests showed that our methods were correct.

\section{Conclusion}

The movement of energy resources from one point to another is an important issue today. In the near future, with the necessity of transporting oil and gas from the rich reserves of the Middle East to Europe via Turkey, the importance of this issue will increase even further. The geographical location of Turkey as a bridge between Asia and Europe is fortuitous. When analyzing existing energy transmission projects and projects planned for the future, it is seen that several transmission line applications will be carried out in Turkey; thus, LCPAbased GIS route determination studies are among the most important technological tools that can be used effectively to reduce the cost of this process, both economically and environmentally.

The MCDM method integrated with GIS technologies can be used effectively in the analysis of multifactorial problems such as route determination. Conventional route determination methods currently give rise to many environmental, economic, sociological, and sustainability problems. Ranking, scoring, and pairwise comparison methods are used for the determination of the weight factors. The pairwise comparison method is used in the route determination process with the TOPSIS method. Subjective evaluations are always involved in determining the weights. Therefore, weights can be changed according to the characteristics of the study area and the ideas of the decision makers. Furthermore, results are affected by the significant variations between weights that have been determined by different methods. Although its application is difficult, the pairwise comparison method is more effective in terms of producing more accurate results and controlling whether the weights are consistent in the process of determining the TP route.

The S-TOPSIS method was effectively used in LCPA applications based on GIS. This study has provided very positive results in determining TP routes with the advantage of the algorithm used in the calculation cost surface. The current route is $84.33 \mathrm{~km}$ in length, while the ESOR found with S-TOPSIS was $77.29 \mathrm{~km}$. When calculating the width of the corridor as $20 \mathrm{~m}$ and the length as 7.04 miles, it was proven that environmental damage due to construction could be prevented on approximately 14 ha. However, this is an economy-saving application, and the final route is essential and applicable with the aspects of environmental sensitivity such as forest areas, stream intersections, or passing protected areas (Table 2). Wildlife, habitats, and nature will be protected as a result.

A local conclusion of this study states that in Turkey, spatial data problems must be eliminated by creating standards for the most important components of the GIS spatial data. A significant part of the project dealt with the difficulties in spatial data collection. The burden of temporal, economic, and labor data collection confirmed this conclusion.

Remote sensing technology and GPS were used to obtain non-available data. It has been proven that these technologies can provide useful data for the generated models with the integration of GIS-MCDM methods. A number of test studies were performed in specially selected areas for the ESOR found with S-TOPSIS land applique and GPS. The accuracy of the spatial data used in this field study was tested, and finally the test results and resulting spatial deviations were determined within the general accuracy limits of the project.

In order to minimize environmental damage, TPs are subject to the Environmental Impact Assessment (EIA) process, which has been established by legislation. At the feasibility stage of a TP project, routes are analyzed in terms of environmental damage, and the TP routes would be revised in instances of extreme environmental degradation. In the case of Turkey, conventional route 
determination methods are commonly used, making it difficult to manage the process effectively. In addition, of the four factors affecting TP routes in Turkey - economics, the environment, sociology, and politics - economics and politics seem to be much more in the forefront than environmental factors.

For this study, we advise that all route planners using GIS and MCDM (especially TOPSIS) solve challenging problems together. Our recommendation for academicians and practitioners studying in similar areas is to create their own GIS extension or tools for their specific studies or related projects. Reliable data should be used because this study directly shows that the success of all these analyses and optimizations lay behind accuracy of spatial data used. As a final declaration, we think nature wasted by using technology in bad ways would be recovered by using technology consciously.

\section{Acknowledgements}

The authors would like to thank the Scientific and Technological Research Council of Turkey (TUBITAK, project No. 111Y041) for financial support from related projects.

\section{References}

1. ZEINOLABEDIN Y., YAHYAPOOR M.S., SHIRZAD Z. The Geopolitics of Energy in the Caspian Basin. Int. J. Environ. Res. 5 (2), 501, Spring 2011, ISSN: 1735-6865, 2010.

2. RANJBAR P., SHAFIEEFAR M., REZVANDOUST J. Modeling of Oil Spill and Response in Support of Decreasing Environmental Oil Effects Case Study: Blowout from Khark Subsea Pipelines (Persian Gulf). Int. J. Environ. Res. 8 (2), 289, Spring 2014, ISSN: 1735-6865, 2014.

3. MARUFUZZAMAN M., EKSIOGLU S.D., HERNANDEZ R. Truck versus pipeline transportation cost analysis of wastewater sludge. Transportation Research Part A. 74, 14, 2015.

4. BALOGUN A., MATORI A., LAWAL D.U., CHANDIO I. Optimal Oil Pipeline Route Selection using GIS: Community Participation in Weight derivation and Disaster Mitigation, 2012 International Conference on Future Environment and Energy, IPCBEE, 28, IACSIT Press, Singapore, 2012.

5. LIDSKOG R., ELANDER I. Sweden and the Baltic Sea pipeline: Between ecology and economy. Marine Policy. 36, 333, 2012.

6. TAVANA M., BEHZADIAN M., PIRDASHTI M., PIRDASHTI H.A PROMETHEE-GDSS for oil and gas pipeline planning in the Caspian Sea basin. Energy Economics. 36, 716, 2013

7. NUSSBAUM M. Pipeline Route Selection: The factors you consider during the routing phase can make or break your pipeline project. Right of Way, January/ February, 2012.

8. NANAY J., STEGEN K.S. Russia and the Caspian region: challenges for transatlantic energy security. Journal of Transatlantic Studies. 10 (4), 343, 2012.

9. WINROW M.G. The Southern Gas Corridor and Turkey's Role as an Energy Transit State and Energy Hub. Insight Turkey. 15 (1), 145, 2013.
10. YILDIRIM T. Turkey's place in the path of the development of common energy politics of the European Union. Journal of International Studies. 6 (2), 94, 2013.

11. GUIMARÃES B., SIMÕES P., MARQUES R. Does performance evaluation help public managers? A Balanced Scorecard approach in urban waste services. Journal of Environmental Management. 91 (12), 2632, ISSN: 03014797, 2010.

12. THOMAIDIS F., MAVRAKIS D. Optimum Route of the South Transcontinental Gas Pipeline in SE Europe using AHP. Journal Of Multi-criteria Decision Analysis. 14, 77, 2010.

13. HUANG Y., FIPPS G., MAAS S.J., FLETCHER R.S. Airborne Remote Sensing for Detection of Irrigation Canal Leakage. Irrig. and Drain, DOI: 10.1002/ird., 2009.

14. JAFARI S., ZAREDAR N. Land Suitability Analysis using Multi Attribute Decision Making Approach. International Journal of Environmental Science and Development. 1 (5), ISSN: 2010-0264, 2010.

15. BALOGUN A., MATORI A., YUSSOF K., LAWAL D.U., CHANDIO I.A. Geographic Information System (GIS) in Offshore Pipeline RouteSelection: Past, Present, and Future. Pensee Journal. 75 (9), 374, ISSN 00314773, 2013.

16. CHOI Y., UM J., PARK M. Finding least-cost paths across a continuous raster surface with discrete vector networks. Cartography and Geographic Information Science. 41 (1), 75, DOI: 10.1080/15230406.2013.850837, 2014.

17. MARTINEZ-GRANA A.M., GOY J.L., ZAZO C. Water and Wind Erosion Risk in Natural Parks - A Case Study in "Las Batuecas-Sierra de Francia" and "Quilamas" Protected Parks (Central System, Spain). Int. J. Environ. Res. 8 (1), 61, ISSN: 1735-6865, 2014.

18. VUKICEVIC J.S., NEDOVIC-BUDIC Z. GIS Based Multicriteria Analysis in Integration of SEA Process Into Planning, Case Study: South West Region, Republic of Ireland. Int. J. Environ. Res. 6 (4), 1053-, ISSN: 1735-6865, 2012.

19. 19. YILDIRIM, V., YOMRALIOGLU, T., NISANCI, R. A Raster Based Geospatial Model for Natural Gas Transmission Line Routing, Book Chapter, Natural Gas Extraction to End Use. 101-118, Rijeka, Crotia, ISBN; 978-953-51-0820-7, 2012.

20. BAGLI S., GENELETTI D., ORSI F. Routing of power lines through least-cost path analysis and multicriteria evaluation to minimize environmental impacts. Environmental Impact Assessment Review. 31, 234, 2011.

21. EFFAT H., HASSAN O.A. Designing and evaluation of three alternatives highway routes using the Analytical Hierarchy Process and the least-cost path analysis, application in Sinai Peninsula, Egypt. The Egyptian Journal of Remote Sensing and Space Sciences. 16, 141, 2013.

22. PINTO F., FIGUEIRA J., MARQUES R. A multi-objective approach with soft constraints for water supply and wastewater coverage improvements. European Journal of Operational Research. 246 (2), 609, ISSN: 1435-246X, 2015.

23. AISSI H., CHAKHAR S., MOUSSEAU V.GIS-based multicriteria evaluation approach for corridor siting. Environmental and Planning B: Planning Design. 39 (2), 287, 2011.

24. SILVA S., ALMEIDA L., DIAS L. Biogas plants site selection integrating Multicriteria Decision Aid methods and GIS techniques: A case study in a Portuguese region. Biomass and Bioenergy. 71, 58, 2014.

25. GARCIA J.L., ALVARADO A., BLANCO J., JIMENEZ, E., MALDONADO A.A., CORTES G. Multi-attribute 
evaluation and selection of sites for agricultural product warehouses based on an Analytic Hierarchy Process. Computers and Electronics in Agriculture. 100, 60, 2014.

26. OUMA Y.O., YABANN C., KIRICHU M., TATEISHI, R. Optimization of Urban Highway Bypass Horizontal Alignment: A Methodological Overview of Intelligent Spatial MCDA Approach Using Fuzzy AHP and GIS. Advances in Civil Engineering, ID 182568, 26, http://dx.doi. org/10.1155/2014/182568, 2014.

27. FERRETTI V., POMARICO S. Integrated sustainability assessments: a spatial multicriteria evaluation for siting a waste incinerator plant in the Province of Torino (Italy). Environ Dev Sustain. 14, 843, DOI 10.1007/s10668-0129354-8, 2012.

28. DURDURAN Ş.S. A decision making system to automatic recognize of traffic accidents on the basis of a GIS platform. Expert Systems with Applications. 37, 7729, 2010.

29. OCALIR E., ERCOSCUN O., TUR R. An integrated model of GIS and fuzzy logic (FMOTS) for location decision of taxicab stands. Exp Sys App. 37, 4892, 2010.

30. KOWKABI L., RAHMAN A.R., BADRI A., RAJAEE A. The Application of Fuzzy Multi-Attribute Group Decision Making to Prioritize the Landscapes with high Ecological value: Khoshk River in Shiraz. Int. J. Environ. Res. 7 (2), 423, ISSN: 1735-6865, 2013.

31. VAFAEI F., HARATI A.N. Strategic Management in Decision Support System for Coastal Flood Management. Int. J. Environ. Res. 4 (1), 169, 2010.

32. DEMETRIOU D., SEE L., STILLWELL J. A Spatial MultiCriteria Model for the Evaluation of Land Redistribution Plans. Int. J. Geo-Inf. 1, 272, DOI:10.3390/ijgi1030272, 2010.

33. RODRIGUES J.C., SIMAO A., ANTUNES C.H. A GISbased multicriteria spatial decision support system for planning urban infrastructures. Decision Support Systems. 51, 720, 2011.

34. SANTOS L., RODRIGUES C., ANTUNES C.H. A web spatial decision support system for vehicle routing using Google Maps. Decision Support Systems. 51, 1, 2011.

35. CHEN Y., YU J., KHAN S. Spatial sensitivity analysis of multi-criteria weights in GIS-based land suitability evaluation. Environmental Modelling \& Software. 25 (12), $1582,2010$.

36. DA CRUZ N., MARQUES R. A multi-criteria model to determine the sustainability level of water services. IWA. Water Asset Management International pp. 16-20. 1814-5434. 2013.

37. WANG Z.X., WANG Y.Y. Evaluation of the provincial competitiveness of the Chinese high-tech industry using an improved TOPSIS method. Expert Systems with Applications. 41, 2824, 2014.

38. LOURENZUTTI R., KROHLING R.A. The Hellinger distance in Multicriteria Decision Making: An illustration to the TOPSIS and TODIM methods. Expert Systems with Applications. 41, 4414, 2014.

39. PAZAND K., HEZARKHANI A., ATAEI M. Using TOPSIS approaches for predictive porphyry $\mathrm{Cu}$ potential mapping: A case study in Ahar-Arasbaran area (NW, Iran). Computers \& Geosciences. 49, 62, 2012.

40. CHURCH R.L., MURRAY A.T. Business site selection, location analysis and GIS. John Wiley and Sons, New Jersey, 2009.

41. GONCALVES A.B. An extension of GIS-based least-cost path modelling to the location of wide paths. International Journal of Geographical Information Science. 24 (7), 983, 2010.

42. TUIK. http://www.tuik.gov.tr/Start.do., 2014. 